\title{
Family Separation, Reunification, and Intergenerational Trauma in the Aftermath of Human Trafficking in the United States
}

\author{
Kamolwan 'Juli' Juabsamai and Ileana Taylor
}

\begin{abstract}
Family reunification is a complex part of a survivor's journey; its processes long, arduous, and unassured. This article seeks to examine the intricacies of human trafficking and family separation in migration, and intergenerational trauma following family reunification. The authors apply theoretical frameworks and concepts established by literature on migration and trauma, and provide a case study to explain the implications of family separation that occurs during and after the survivor's human trafficking experience. Written from the perspective of social service providers, this article also provides a look at life after trafficking and how the individual's worldview is altered by the trauma endured, resulting in possible intergenerational transmission of trauma from parent to child. The article explains the family's process of moving from crisis back to balance, and the need for adjustment and adaptation, flexibility and cohesion in finding resilience. Finally, the authors discuss family resiliency frameworks as empowering models for serving survivors of human trafficking and their families during the reunification process. With the appropriate support, families can move forward in their journey towards healing.
\end{abstract}

Keywords: human trafficking, trauma, intergenerational transmission of trauma, family reunification, family resiliency

Please cite this article as: K Juabsamai and I Taylor, 'Family Separation, Reunification, and Intergenerational Trauma in the Aftermath of Human Trafficking in the United States', Anti-Trafficking Review, issue 10, 2018 , pp. 123-138, www.antitraffickingreview.org

\section{Introduction}

In the aftermath of human trafficking, family reunification is a long and complex road that has received little attention in the anti-trafficking field. Family reunification refers to the reunion of a family after one or more members have been living in a foreign country for a period of time. Many families have been separated for numerous years with little end in sight. For some survivors, family reunification can be consolation for the trauma that they have endured, but not the end of the trauma. Time has passed, children have grown, and lives and relationships have changed. ${ }^{1}$ This article looks at the implications of family separation as a result of human trafficking and migration, and delves into a review of the literature studying the possible intergenerational transmission of trauma in the aftermath of human trafficking and family reunification.

This article draws on literature from other fields, such as migration, to better understand the intricacies of family separation and the concept of transnational families, and their impacts. While little research has been conducted on family reunification with trafficking survivors, some research exists on family separation and reunification in relation to migration. This paper aims to bridge the two and contribute to knowledge on family resilience in the aftermath of trafficking and trauma.

The narrative presented is an amalgamation of true accounts of survivors of labour trafficking in the United States with whom we have worked (all names are changed to protect their privacy). Their stories are representative of trafficked individuals facing family separation and the challenge of successful reunification. The following two sections will focus on the concept of intergenerational transmission of trauma from parent to child after human trafficking and family separation. We touch on the Theory of Ambiguous Loss, ${ }^{2}$ as well as

1 D A Boehm, Intimate Migrations, New York University Press, New York, 2012.

2 P Boss, Loss, Trauma, and Resilience: Therapeutic work with ambiguous loss, W.W. Norton \& Company, Inc., New York, 2006. 
Attachment Theory, ${ }^{3}$ and their utilisation in relation to transnational families and family separation, with a focus on the intergenerational transmission of trauma following human trafficking and family reunification, rather than during the trafficking situation. We define trauma as an emotional response to the abuse and exploitation endured by the survivor with regard to the trafficking situation. It is important to note that trafficking does not necessarily yield a particular set of trauma responses as the experiences of each individual vary. The ability and time it takes to cope and heal are different for each. ${ }^{4}$ For many clients, managing trauma is an ongoing battle with many layers to address.

In the final section, we introduce family resiliency frameworks as a means of affording further recommendations to all stakeholders, particularly social service providers, to look at strengths and resilience of clients and families while providing services.

\section{Family Reunification: An overview}

For some survivors of human trafficking, family reunification can be an important part of their journey. For some, it is a happy reunion - a reward for the hardship endured over the period of separation. However, following the excitement and anticipation, parents and children have to become reacquainted. Children have to adapt to a new environment and adjust to a life with the absent parent towards whom they may have ambiguous feelings due to the separation. This challenge may not be long-term as the children could adjust quickly to the new country, its norms and cultures, and families can access their resilience to overcome the long separation and improve their relationship. ${ }^{5}$

The United States government aids the reunification process by offering support and protections for survivors of human trafficking and their families under the Victims of Trafficking and Violence Protection Act 2000 (also known as the Trafficking Victims Protection Act). Under its provisions, certified survivors of human trafficking are able to apply for a T-Visa, which enables them to remain in the US and to sponsor their spouse and children under 21 years of age to come to the United States too. This visa is granted only to immediate family members. Upon arrival, the family members receive a Derivative T-Visa, which is similar to refugee status. The law provides access to federal and state benefits, such as Supplemental Nutrition Assistance Program (SNAP), and medical insurance (Medicaid).

Federal and state funding also allows survivors and their families to receive case management, legal assistance, and emergency assistance through social service providers. The duration of the support varies from programme to programme. The services help reunified families get back on their feet prior to applying for public assistance, or finding employment, which could take time. When survivors of traumatic experiences receive the means and support they need, they are better able to manage the emotional, psychological and physiological stressors caused by the traumatic experience. ${ }^{6}$

\section{Louis: A case study}

The authors use the narrative of the case study to discuss the theoretical frameworks presented herein.

3 As described in M D Ainsworth, M C Blehar, E Waters, and S N Wall, Patterns of Attachment: A psychological study of the strange situation, Lawrence Erlbaum, New Jersey, 1978.

4 D Brennan, Life Interrupted: Trafficking into forced labor in the United States, Duke University Press, 2014, p. 117.

5 N B Busch-Armendariz, M B Nsonwu and L C Heffron, 'Human Trafficking Victims and their Children: Assessing needs, vulnerabilities, strengths, and survivorship', Journal of Applied Research on Children: Informing policy for children at risk, vol. 2, issue 1, 2011.

6 A Gitterman, Handbook of Social Work Practice with Vulnerable and Resilient Populations, Columbia University Press, 2nd edition, 2001. 
Louis came to the United States in 2010 to seek work after losing his job as a nurse in his home country of the Philippines during the economic crisis. Unsuccessful at finding employment, Louis responded to an advertisement on the Internet seeking staff to work in the hospitality industry in the United States. Like many other international migrants, Louis decided to leave home in order to provide for his family. ${ }^{7}$ Researchers suggest that at the root of migration behaviour is the desire to improve or maintain quality of life. ${ }^{8}$ This position promised a higher salary than what he was making at his nursing job. Louis determined that during these difficult times, it was worth the sacrifice. He met with $\mathrm{Mr} \mathrm{M}$ who had posted the ad. He informed Louis that to qualify for the position, he had to pay an application fee of USD 2,000, fund his own visa, airfare, and pay an honorarium to the agency. Louis was assured by Mr M that all expenses would be covered once he arrived in the US, so he borrowed money from his extended family. He believed that once in the United States, he would make enough money to repay his relatives.

Life in the United States was not what he had imagined it would be. Louis worked long, gruelling hours at a chain hotel in a city he had never heard of before. His salary was one quarter of what was promised in the contract, and he was forced to sleep in a one-bedroom apartment with six other workers. Louis and the other workers were escorted to and from the apartment each day by guards who also stood watch at night and verbally abused them and threatened them with violence. His freedom of movement was severely restricted. The traffickers also told the workers that they would be arrested and deported if they tried to escape. Louis' health began to deteriorate due to the abuse, lack of food and proper nutrition.

After paying the fees for transportation to and from work, food and rent at the end of the month, Louis had barely enough money to send home to his family for his children's basic schooling, or repay his relatives. He was deeply ashamed to tell his family about what life was like in the United States, so he avoided calling them. During the rare times when he would call, his children were reluctant to speak to him. As other scholars have noted, children and parents often become estranged during their time apart. ${ }^{9}$ Louis' hope to provide for his family was shattered by the reality of his human trafficking experience. Anthropologist Denise Brennan writes about formerly trafficked individuals who do not tell their families about their trafficking situation, either as it is unfolding or after. ${ }^{10}$ Similarly, Louis was not able to communicate with his family during his captivity and felt guilty and ashamed for falling prey to unscrupulous individuals both during and after the trafficking situation.

Louis was able to leave his trafficking situation after he befriended a co-worker at the hotel. He told this person of his predicament and together with his co-worker, they devised a plan to escape, although it would mean that they would be undocumented. Louis, together with two other co-workers, managed to leave and travel to New York City where he had a distant cousin. Soon after, Louis found a job as a home health aide through an advertisement online. He worked six days a week, up to 16 hours a day taking care of an elderly man. Although the hours were sometimes gruelling, Louis was free to come and go as he pleased. The elderly man was kind to him, and never asked him about his immigration status. Importantly, the salary was good. This afforded Louis the opportunity to save more money for his family.

7 N N Sørensen and I M Vammen, 'Who Cares? Transnational families in debates on migration and development', New Diversities, vol. 16, no. 2, 2014, pp. 89-108.

8 G F DeJong, D B Root, and R G Abad, 'Family Reunification and Philippine Migration to the United States: The immigrants' perspective', The International Migration Review, vol. 20, no. 3, 1986; L J Abrego, Sacrificing Families: Navigating laws, labor, and love across borders, Stanford University Press, 2014, p. 26.

9 J Dreby, Everyday Illegal: When policies undermine immigrant families, University of California Press, 2015, p. 175.

10 Brennan, 2014, p. 78. 
Approximately two months after his escape, Louis was referred to Safe Horizon's Anti-Trafficking Program (ATP) by a friend who had received assistance there previously. The programme assists survivors through the provision of social and legal services. At ATP, he met with a social worker. Louis recounted what he could remember of his story to his social worker. He spent most of the session staring at the ceiling, his voice barely above a whisper. He told his story without emotions or facial expressions, and appeared detached-common trauma reactions that survivors of trafficking experience. ${ }^{11}$ When asked about his family, he said he was certain that he had pushed them away, but was finally re-establishing ties with them by showing them more confidence in his ability to care for them financially, despite the long hours that he worked and the small sum he could send home.

Throughout the counselling phase, Louis reported insomnia, going days with little sleep. He also experienced disconnection from his trauma and had difficulty focusing, such that while taking public transportation to familiar places like home and work, he would find himself in different locations than intended. He was hypervigilant, always aware of his surroundings. He had panic attacks, which caused him to think that he was experiencing a heart attack, but felt unable to seek medical attention due to his immigration status. He also reported that he would sometimes have to leave the subway because he felt locked in. He experienced flashbacks and rumination, which consisted of involuntary re-experiencing of the verbal and emotional abuse that he had endured at the hands of the traffickers. He thought constantly about his experience, which contributed to his ongoing feelings of depression. ${ }^{12}$ Furthermore, he had skin rashes that had no explanation, possibly a somatic manifestation of the trauma after a trafficking situation. ${ }^{13}$

During this time, Louis continued to work with his social worker, receiving trauma-focused counselling, as well as practical assistance in the form of gift cards for food and personal care items, and round-trip subway passes. This alleviated some of the financial burden that he felt and allowed him to save more money for his family. Together, Louis and his social worker created a safety plan to address some of his feelings of hypervigilance and ensure that he had a support system. Furthermore, they explored his reactions to the trauma, and worked to develop coping skills.

Louis also worked with ATP's legal team over time to obtain his T-Visa, and apply for Derivative T-Visas for his wife and children. It took him time to be comfortable with his social worker and attorney, as he indicated many times that he had difficulty trusting others after being 'duped' by Mr M and his traffickers. This lack of trust following an experience like Louis' is also described by Brennan, as common after being cheated and abused. She goes on to state that after leaving the trafficking situation, survivors are expected to place their trust in strangers, such as those who could possibly help them-i.e. law enforcement, social workers, prosecutors, etc. This expectation can be confusing for survivors, and it can be particularly difficult to gauge who can and should be trusted based on who is able and willing to assist them. ${ }^{14}$ Louis described his anxiety and lack of trust as factors for missing appointments, which further delayed his T-Visa application, and as a result, reunification with his family.

By that time, Louis was regularly sending money home and communicating with his family. Money plays an important part in repairing trust in a transnational family, as documented in other scholarly studies. ${ }^{15}$ As a result, Louis began to regain the trust of his wife and eldest children, who were more willing to talk to him when he called. Thus, when the time came to fill out the paperwork for the Derivative T-Visas, his family was willing to cooperate. After many months of waiting, multiple interviews, and copious paperwork, the family's Derivative T-Visas were approved. Louis' social worker coordinated with the International Organization for Migration (IOM) to assist with the logistics of family reunification, including expenses related to the family's visas and travel. After five long years, the family was reunited in August 2015 in New York City.

11 B Banović and $\check{Z}$ Bjelajac, 'Traumatic Experiences, Psychophysical Consequences and Needs of Human Trafficking Victims', Vojnosanitetski Pregled, vol. 69, no. 1, 2012.

12 Ibid.

13 E K Hopper, 'Underidentification of Human Trafficking Victims in the United States', Journal of Social Work Research and Evaluation, vol. 5, no. 2, 2004.

14 Brennan, 2014, p. 122.

15 C A Solheim and J Ballard, 'Ambiguous Loss Due to Separation in Voluntary Transnational Families', Journal of Family Theory \& Review, vol. 8, issue 3, 2016, pp. 341-359. 
However, family reunification is not always easy. ${ }^{16}$ Although their communication prior to arrival had been positive, after their arrival it was challenging for them all to adjust to this new lifestyle. Louis' children had no idea how to react to this strange, new man in their lives. They regarded him with fear and fragility, never knowing what might make him angry and set him off.

At ages 5, 7, 12 and 14, the children had grown up without their father. Marie, Louis' wife, was four months pregnant when he left for America, and their youngest son, Joseph, was born in his absence. In applying for the Derivative T-Visa, Joseph did not have proper documentation and had to undergo DNA testing to prove that Louis was his father, as Louis was not present during Joseph's birth. This caused a great deal of stress in the family. Joseph began acting out towards his father, as he considered Louis a stranger. As other scholars have noted, children who are separated from their parents tend to have difficulties upon separation and reunification. ${ }^{17}$ Mark, their second youngest, avoided Louis for the same reason. Louis shared that he did not know how to bond with his two younger children. He stated that they seemed to resent him, and constantly told him that they wanted to go home to their Papa, their maternal grandfather who had been a father figure in Louis's absence.

He also had difficulty relating to his two older children, who resented him for taking them away from their friends back home. Louis did not know how to react. His hopes of a happy family reunification were met with sadness as he struggled to bond with his children, who resented him for moving them to a foreign country where they were required to learn a new language, lifestyle, and customs. When asked how he was feeling about his family being in the US, Louis responded to his social worker, 'It is so difficult for me to believe how I was so easily manipulated [by my traffickers]. I am so ashamed to look at my wife and children in the eyes, because I lost everything we worked so hard for.'

\section{Implications in the Aftermath}

The discussion of parental migration and family separation is complex. The concept of transnational families, where family members live some or most of the time separated from each other across national borders, is considered a 'temporary phenomenon' with family reunification as the end goal for all members. ${ }^{18}$ There is a 'common longing for good jobs, decent pay, citizenship, and family reunification'. ${ }^{19}$ For nearly all of our clients, this was their hope in coming to the US: an opportunity to provide for their family, and improve or maintain their quality of life. Unfortunately, this notion may leave them vulnerable to abuse, abandonment and exploitation. ${ }^{20}$

For many, this risk is one worth taking, but it comes at a price. ${ }^{21}$ Research demonstrates that family members, especially children, may benefit economically from remittances; however, they may suffer emotionally from prolonged separation. ${ }^{22}$ In her research, Abrego suggests that children associate remittances with love. ${ }^{23}$ When a parent is able to send home large and consistent amounts of money, the children were more likely to appreciate their parents' sacrifices, and maintain strong, positive contact. The remittances make the separation

16 U D Berg, Mobile Selves: Race, migration, and belonging in Peru and the US, New York University Press, New York, 2015, pp. 108-109.

17 Abrego, 2014, pp. 159-160.

18 Landolt and Da, 2005, as cited in V Mazzucato and D Schans, 'Transnational Families and the Well-being of Children: Conceptual and methodological challenges, Journal of Marriage and Family, vol. 73, issue 4, 2011, pp. 704-712.

19 Brennan, 2014, p. 118.

20 International Organization for Migration, 'Migration and families', 2014.

21 Sørensen and Vammen, 2014

22 V Mazzucato and D Schans; C Suárez-Orozco, H J Bang, and H Y Kim, 'I Felt Like my Heart was Staying Behind: Psychological implications of family separations \& reunifications for immigrant youth', Journal of Adolescent Research, vol. 26, issue 2, 2010; C Suárez-Orozco, I L G Todorova, and J Louie, 'Making up for Lost Time: The experience of separation and reunification among immigrant families', Family Process, vol. 41, no. 4, 2002; R S Parreñas, 'Mothering from a Distance: Emotions, gender, and intergenerational relations in Filipino transnational families', Feminist Studies, vol. 27, issue 2, 2001; A Fresnoza-Flot, 'The Bumpy Landscape of Family Reunification: Experiences of first- and 1.5generation Filipinos in France', Journal of Ethnic and Migration Studies, vol. 41, no. 7, 2015; N A Schapiro, S M Kools, S J Weiss, and C D Brindis, 'Separation and Reunification: The experiences of adolescents living in transnational families', Current Problems in Pediatric Adolescent Health Care, issue 43, 2013.

23 Abrego, 2014, p. 83. 
worthwhile, as they provide life improvements for the children and proof of the parent's continued commitment to the family. On the contrary, when the remittances were very little or lacking, children felt abandoned and resentful, and deemed the separation unjustified.

In Abrego's interviews with fathers who, due to economic hardship, were unable to, rarely able to, or only able to send little remittances home, she found that they felt immense shame. Like Louis, they were reluctant to contact their families if they could not send remittances. Some stated that they felt 'irresponsible' as they did not have anything to show for their hard work, nor a reason to explain their separation. ${ }^{24}$

Furthermore, the family members left behind may experience what Pauline Boss termed 'ambiguous loss.' 25 The Theory of Ambiguous Loss refers to a state in which there is no closure. Boss identifies two kinds of ambiguous loss: one in which the family member is psychologically present, but physically absent; and one in which they are physically present, but psychologically absent. This can be applied to survivors of human trafficking too. As such, when the family is separated, the absent parent is physically unavailable, but may try to be available psychologically by sending some remittances or communicating with their family members through telephone calls and other means. ${ }^{26}$

In Louis' case, he left his family believing that he would work and send his earnings home. He believed that this would be a temporary arrangement to get his family back on their feet. However, the pressure to provide for his family led to vulnerability and exploitation, which has the potential to be severely traumatising.

As a result of separation and continued financial hardship, children of migrants report feeling abandoned. They feel withdrawn and have ambivalent feelings towards their migrant parent. ${ }^{27}$ During the separation, they grow accustomed to living without the migrant parent and become more independent. ${ }^{28}$ Consequently, there is a breakdown in communication between parent and child. Parents report having trouble disciplining or expressing authority. The results of this disconnect between parent and child is difficult to repair. ${ }^{29}$

John Bowlby's Attachment Theory ${ }^{30}$ helps to explain Louis' younger children's behaviour. Bowlby studied the interactions of parents and children following temporary separation and observed the children's mourning behaviour and response upon reunification. Louis' younger children had difficulty connecting and engaging with him due to the separation endured during his trafficking experience. As such, his youngest son did not know him at all. This is akin to the experiences of other migrants as well, as relayed by the numerous narratives told by Dreby. ${ }^{31}$ Suarez-Orozco et al., in their research found that separation causes estrangement, ${ }^{32}$ and as with Louis and his younger children, the years of separation and the birth of the youngest child in his absence were difficult to overcome.

\section{The Intergenerational Transmission of Trauma}

Louis' relationship with his children is an example of how difficult experiences can affect the family and shows that the painful scars of trauma are often felt by the next generation. ${ }^{33}$ Abrams suggests that intergenerational trauma is not confined to one set of experiences and posits that it is 'widespread'. A growing number of researchers are utilising literature derived from Bowlby's Attachment Theory to better understand the intergenerational transmission of trauma. ${ }^{34}$ Brothers writes that trauma may be transmitted in day-to-day

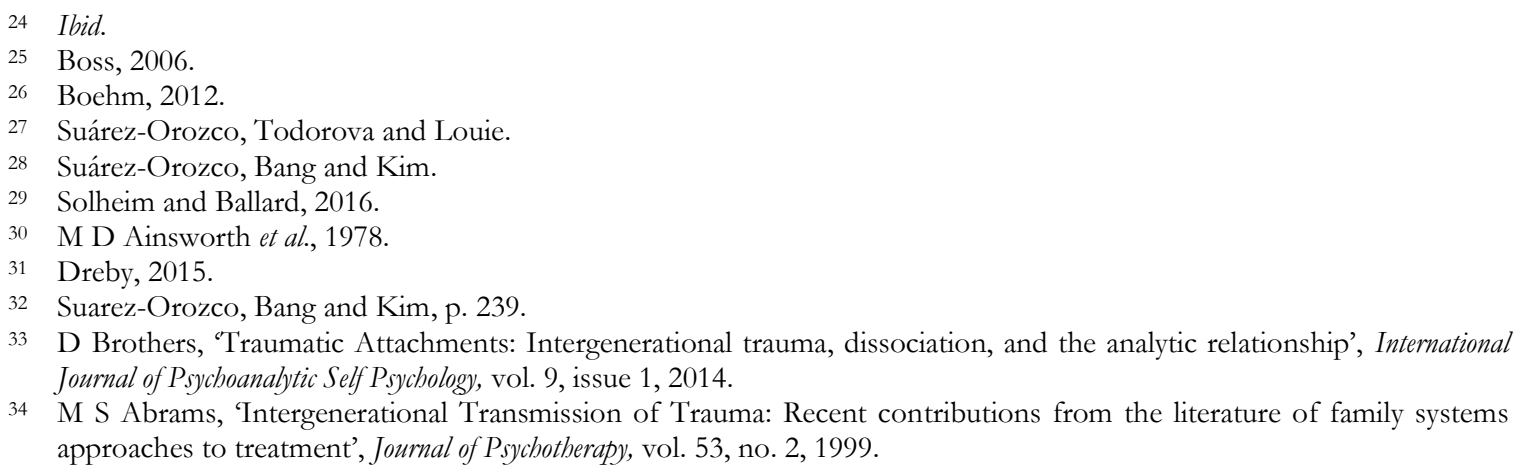

34 M S Abrams, 'Intergenerational Transmission of Trauma: Recent contributions from the literature of family systems approaches to treatment', Journal of Psychotherapy, vol. 53, no. 2, 1999. 
familial relationships. Children may develop 'disorganized/disoriented attachment patterns' as a result of the responses of their parent(s)' traumatic experiences. ${ }^{35}$

The responses and availability of these parents have the ability to impact their child's response to relationship formation throughout their lifetime. In a study of mother-infant prenatal attachment, Schwerdtfeger and Nelson Goff discuss the relationship between interpersonal trauma and resulting post-traumatic stress disorder (PTSD), and its transmission to the infant or child. According to Walker, as cited in Schwerdtfeger and Nelson Goff, adults who have suffered trauma may or may not be emotionally or functionally approachable. Walker further states that parents may show abusive behaviour and thus affect their children. ${ }^{36}$ Although these could be applied to trafficking survivors, more longitudinal research is needed.

In Louis' case, the children now have direct exposure to his trauma symptoms. They witness the psychological pain that their father feels, and it reflects upon their reactions. His trauma responses are a cause for family disruption. Because he is hypervigilant, less trusting and extra cautious, the family members tend to have similar reactions. Catherall, as cited in Abrams, proposes that mistrust can at times be 'transmitted' without the survivor being aware, ${ }^{37}$ thus making the attachment patterns within the family rigid and constricted. ${ }^{38}$

Louis' trafficking experience transformed his life and his view of the world. His health had suffered due to lack of proper nutrition; his skin condition, and the memories of his trafficking experience were often on his mind. He became anxious and had difficulty trusting others. He hated to burden his family with details of the experience, but the symptoms rang clear. Louis' symptoms fit most of the categories for complex trauma. ${ }^{39}$ This affects his day-to-day life, including his relationship with his children. Prior to coming to the United States, Louis had a close and supportive relationship with them. Filipino families have a tendency for affection and closeness, and in their relationships, they depend on each other for support. ${ }^{40}$ Louis' traumatic experience altered the family dynamic and his relationship with his children.

The effects of Louis' trauma were affecting his family members by inadvertently transferring his distorted view of the world to his children, causing what Abrams describes as 'secondary trauma', or the stress of living or working with trauma survivors. ${ }^{41}$ Trauma can be transmitted via 'sensations and emotions'. ${ }^{42}$ Philips, as cited in Menzies on his work with indigenous communities in Canada, suggests that trauma survivors who do not know how to cope with their traumatic experience 'often take their pain and hurt out on the people they love the most— their families'. ${ }^{43}$

For so long during the family reunification process, Louis viewed his children as his hope for the future and worked hard to give them the future that he thought they deserved. However, upon their arrival to the United States, he became discouraged by the distance that existed between them. He became overwhelmed by his feelings of sadness, anger and aggressiveness, and his children did not know how to react. This affected the quality of their relationship and the bond between them.

\section{Family Resiliency and Further Recommendations}

35 Brothers, 2014.

36 K L Schwerdtfeger and B S Nelson Goff, 'Intergenerational Transmission of Trauma: Exploring mother-infant prenatal attachment', Journal of Traumatic Stress, vol. 20, no. 1, 2007, pp. 39-51.

37 Abrams, 1999.

38 Brothers, 2014.

39 B C Johnson, 'Aftercare for Survivors of Human Trafficking', Social Work \& Christianity, vol. 39, no. 4, 2012, pp. 370389.

40 'Cultural Differences in Parenting Practices: What Asian American families can teach us', Frances McClelland Institute, University of Arizona, vol. 2, no. 1.

41 Abrams, 1999.

42 A Connolly, 'Healing the Wounds of our Fathers: Intergenerational trauma, memory, symbolization and narrative', Journal of Analytical Psychology, vol. 56, issue 5, 2011, pp. 607-26.

43 P Menzies, 'Intergenerational Trauma from a Mental Health Perspective', Native Social Work Journal, vol. 7, 2010; Abrams, 1999. 
The Family Resilience Framework was developed on the premise that, 'Although some families are shattered by crisis or chronic stresses, what is remarkable is that many others emerge strengthened and more resourceful.' Walsh posits that this framework as an intervention applies a strengths-based practice model to clinical practice, emphasising the empowerment and competence of a family to overcome adversity using key processes that 'mediate the adaptation of all members and the family unit'.44

Likewise, Patterson describes the Family Adjustment and Adaptation Response (FAAR) model, which she posits can help families to adapt and adjust. The FAAR model suggests two phases in family resilience: adjustments and adaptations separated by family crises. Whereas the adjustment phase is seen as the 'stable period', the adaptation stage is seen as the stage where family members try to bring back 'homeostasis', or balance into the family unit by looking for new ways to communicate and cope, lessen the pressures, and see their particular situation in a new light. ${ }^{45}$ These two stages of FAAR are compatible with the Family Resilience Framework as it helps the family to move forward, utilise more balanced interactions, and process the traumatic experience together.

We suggest that by utilising the Family Resilience Framework and the FAAR model, service providers can work with a family like Louis' to apply key processes as outlined by Walsh to 'adapt and function competently' following a traumatic experience. This is greatly beneficial in order to restore family cohesion and homeostasis upon reunification after the trafficking experience. Families like Louis' can begin to heal by participating in family counselling or individual cognitive therapy guided by the Family Resilience Framework.

The key processes that Walsh states are separated into three categories: 1) belief systems, 2) organisational patterns, and 3) communication/problem-solving. Family belief systems refer to shared 'constructions of reality [which] emerge through family and social transactions'. These belief systems can change with varying experiences that the family undergoes, such as crisis and trauma. Positive family organisational patterns are characterised by the flexibility to adapt to stressful situations, interconnectedness and cohesion, and having social and economic resources to support the family. Problem-solving and conflict management, according to Walsh, must be collaborative, resourceful and respectful in order to foster family resilience.

Louis' social worker at ATP used the Family Resilience Framework by adapting the key processes to fit the family's needs. Like in the Family Resilience Framework, the social worker assisted the family in recognising signs of trauma and secondary trauma that may trigger Louis and his family members. The social worker assisted the family in learning how to adjust and adapt as a unit in the midst of crisis, and linked the family to social and economic resources in the community. This alleviated stress and helped them form a cohesive bond in both their family and new homeland. They learnt new ways of communicating their feelings respectfully and effectively, and after several counselling sessions, they committed to collaborating as a family to use the skills they learnt. Utilising methods similar to the three key processes, the family became more open to communication, and were able to readjust their belief systems and adapt to stressful situations. By doing so, they felt empowered. As Abrams states, 'There is a critical need for constructive intervention on the level of the individual, family, and environment to prevent further psychological damage. ${ }^{36}$ Thus, service providers may consider utilising these models and adapt them to their client-centred practice.

Louis' family, with the assistance of their social worker, slowly began to heal and continue on the path towards recovery and reconnection. Louis and his wife learnt to navigate the social service system while working with the social worker, which helped them to become more independent. They were able to apply for and obtain public benefits and other services for the family on their own. Furthermore, through counselling, Louis and his family were able to make meaning of the hardship they had experienced. These actions utilise empowering frameworks to encourage the family to function competently as a unit and reach homeostasis again.

More longitudinal research is necessary in this field to better understand the effects of family reunification on both the survivor of human trafficking and the family. While the concepts and theories developed through research on migrants can be applied, in part, to understanding families impacted by trafficking, the experiences and struggles of trafficking survivors are unique due to the complex, and often long-term, trauma.

44 F Walsh, 'Family Resilience: A framework for clinical practice', Family Process, vol. 42, issue 1, 2003.

45 J M Patterson, 'Families Experiencing Stress', Family Systems Medicine, vol. 6, no. 2, 1988, pp. 202-237.

46 Abrams, 1999. 
As we make progress in anti-trafficking work, it is necessary to be nuanced in how the needs of survivors and their families are assessed and addressed across all disciplines, including social sciences, anthropology and public policy. Any support to survivors and their families on their journey towards well-being must include: a holistic look at the impact that separation has on the family; the effects of trauma on the individual, resulting in the possible intergenerational transmission of trauma; and solutions that assist the family as they work to rebuild bonds.

Kamolwan 'Juli' Juabsamai, MSW, is a Thai-American woman from Connecticut. In 2017, she graduated from Fordham University's Graduate School of Social Service where she obtained her MSW with a focus in Community-Based Practice and Leadership. Juli has diverse experience in the field of anti-trafficking, working with organisations in the New York Metro Area, as well as abroad. She also specialises in advocacy, fundraising, case management, and trauma-focused supportive counselling with survivors. Currently, Juli works as a Social Worker at Safe Horizon's Anti-Trafficking Program. Juli also holds a Bachelor of Arts degree in International Relations from Suffolk University. Email: juli.juabsamai@safehorizon.org.

Ileana Taylor has been working in the Safe Horizon Anti-Trafficking Program since its inception in 2001 as an Intensive Case Manager. Ileana received her MSW from Adelphi University in 2015 and her LMSW from the State University of New York in March 2016. Ileana holds an Associate's Degree in Mental Health from LaGuardia Community College and a certificate from the International Trauma Studies Program at New York University. Ileana served as a Student-Member-at-Large of the National Association of Social Workers for the 2013-2014 term. Ileana was the recipient of the 2014-2015 Latino Social Work Coalition Scholarship. Email: ileana.taylor@safehorizon.org. 